\title{
Prensa y crítica ante la primera exposición regional de Filipinas (1893-1895)
}

\author{
M. ${ }^{a}$ del Valle Álvarez Maestre \\ Universidad de Córdoba
}

En septiembre de 1893, don Ángel Avilés Merino, director general de Administración Civil, propone al ministro de Ultramar, don Antonio Maura, la celebración de un certamen donde las Filipinas mostraran al resto del mundo sus avances técnicos, agrícolas e industriales, que se inauguró el 23 de enero de 1895. Este trabajo explica las diferentes reacciones de la prensa filipina de la época ante este acontecimiento, desde su anuncio en marzo de 1894 hasta febrero de 1895. A través de ella, podemos tener una idea sobre los hábitos de vida, las costumbres y el comportamiento de los habitantes de las Islas, su participación en la preparación de la exposición, las fiestas que se proyectaron para asegurar el mayor número de visitantes, el grado de utilidad que los periódicos otorgaban a esta celebración y el estado socioeconómico en el que se encontraba el archipiélago en este periodo. Las fuentes utilizadas son los fondos de prensa filipina que se encuentran en la Biblioteca Municipal de Córdoba, fruto de la donación a la misma de la biblioteca particular del señor Avilés.

La fundación de la ciudad de Singapur en 1824, el inicio al tráfico comercial de algunos puertos chinos en 1840 y sobre todo la apertura del canal de Suez en 1869, que acortó la distancia entre las Islas y la península, pusieron de relieve el potencial de las Filipinas, que tras la pérdida de los territorios americanos dejaron de ser una zona "olvidada" para considerarse un filón a explotar.

Los primeros signos de esa voluntad de cambio se vieron tras la Constitución de 1869, donde se preveía la representación de los habitantes de Cuba y Puerto Rico en las Cortes españolas y anunciaba una ley que reformaría el régimen de gobierno del archipiélago. Consecuencia de esta ley fue la creación, en 1870, del Cuerpo de Administración Civil de Filipinas y el intento de establecer una serie de reformas que asimilaran las instituciones de las Islas a las de la metrópoli.

El estreno de la nueva ruta coincide con los aires de crecimiento económico en España. La política librecambista de Figuerola (1869) abrió las puertas a las inversiones extranjeras, posibilitó la instalación de nuevos ferrocarriles, incrementar la producción agrícola e industrial y mejorar los servicios públicos. Una muestra de la prosperidad adquirida por la burguesía es la exposición universal de Barcelona de 1888.

Como en la metrópolis, en el archipiélago también hubo una etapa de florecimiento económico. En el último tercio del siglo XIX aumentó la 
población urbana, se intensificaron las vías de comunicación con la apertura de la línea oficial de vapores en 1873, que unía mensualmente las Islas con la península, y el tendido del cable submarino entre España y Luzón en 1880. La inauguración del ferrocarril Manila-Dagupan en 1892 posibilitó la explotación de provincias como Tarlac, Pampanga, Pangasinan o Bulacan. En el terreno intelectual, las órdenes religiosas seguían teniendo preponderancia, pero el Estado empieza a tomar conciencia de su papel en la formación, fundando la Escuela de Agricultura de Manila en 1889, la Práctica de Artes y Oficios en 1890 y la Normal Superior de Maestras en 1892.

A pesar de este panorama prometedor, no todo era un camino de rosas. Los moros de Mindanao, tradicionales enemigos de España, se habían sublevado de nuevo. ${ }^{1}$ La epidemia de cólera morbo desatada en Cantón y sobre todo la de peste bubónica, que comenzó en Hong-Kong, empezaban a hacer estragos entre la población y la cuarentena impuesta en los puertos para evitarla destrozaba el comercio. ${ }^{2} \mathrm{El}$ desconocimiento de los asuntos filipinos en España era un hecho y el pueblo filipino, que veía llegar las reformas con cuentagotas, iba deshaciendo el lazo que lo unía con la "Madre Patria".

El contacto entre las dos comunidades se hacía imprescindible y así se comprendió cuando en 1887 se celebró en Madrid una exposición filipina que difundió las costumbres, arte e industrias de sus habitantes, pero esto no era suficiente para contrarrestar las visiones negativas sobre estas islas reflejadas en la prensa. Para que las Filipinas fuesen valoradas en su justo término era necesario que tanto la metrópolis como otras naciones conocieran sus progresos industriales y agrícolas, así como su arte y cultura.

\section{El proyecto de la exposición regional. Opiniones iniciales de la prensa ${ }^{3}$}

Cuando don Ángel Avilés llega a Manila en 1893, como director general de Administración Civil, se da cuenta de la necesidad que tenían las Islas

1 Sobre la política a seguir con los moros de Mindanao había divergencias entre la prensa filipina, así, La Oceanía Española del 18 de febrero de 1894 rechaza todo acercamiento a los rebeldes. En su lugar, propone mano dura y cita como ejemplos la actuación de Inglaterra en El Cabo, la de Francia en Dahomey y Siam y la de Italia, que hizo pasar a cuchillo a 4.000 derviches de Hament Alí.

2 Noticias recogidas por La Oceanía Española de 9 de junio, El Eco de Filipinas de 11 de junio y Diario de Manila de 6 de julio de 1894.

3 Este trabajo lo he hecho consultando la prensa filipina de la época que se encuentra en la Biblioteca Municipal de Córdoba, fruto de la donación que hizo el señor Avilés de su biblioteca particular al Ayuntamiento de Córdoba. Sobre esta donación, ver mi trabajo Fuentes para el estudio de Filipinas en la Biblioteca Municipal de Córdoba, en prensa. 
de un acercamiento a los centros de compra y producción industrial, pues como él mismo escribía a don Ramón Blanco, gobernador general de Filipinas, "el bienestar sólo lo alcanzan en los modernos tiempos, los pueblos que por su ingenio y actividad, más que por los privilegios naturales de que disfrutan, logran salida fácil y colocación segura de sus productos,... es preciso por lo tanto, que los pueblos hasta hace poco tranquilos y sin necesidades por falta de comparaciones, se apresten a la lucha del trabajo si no quieren ser arrollados por la competencia"; ${ }^{4}$ y nada tan eficaz, a su juicio, como la celebración de una exposición regional en Manila, a la que podrían concurrir también las naciones y colonias vecinas, aunque sin invitar oficialmente a sus gobiernos. Su inauguración debería hacerse coincidir con la fiesta cívico-religiosa de San Andrés (30 de noviembre), ya que anualmente se conmemoraba la victoria española sobre el pirata Li-Ma-Hong en 1574. ${ }^{5}$

Avilés consultó la propuesta de la exposición a los principales órganos económicos de las Islas: La Junta Central de Agricultura, Industria y Comercio, Cámara de Comercio, Real Sociedad Económica de Amigos del País y Consejo de Administración de Filipinas. Todos coincidieron en la necesidad de hacer un certamen donde se pusiese de manifiesto el potencial de las Islas, aunque diferían en la forma de hacerlo.

El Sr. Luengo, consejero del consejo de administración, propone que la exposición sea puramente regional, como una demostración de las actividades del archipiélago, pero que también se celebren conferencias científicas e instructivas acerca de la higiene de "estos países", sus religiones y costumbres, agricultura, régimen monetario conveniente a las Islas, tratados de comercio, inmigración y emigración, bellas artes y literatura, medios de estrechar los lazos de unión existente entre España y los naturales y otros. Para conseguirlo, deben tomar parte de la junta permanente representantes de La Trasatlántica y Tabacalera, algunos grandes industriales, el director del Museo-Biblioteca y el padre director del Observatorio Meteorológico. ${ }^{6}$

Por su parte, don Matías García, consiliario de comercio de la Sociedad de Amigos del País, concluía su informe sobre la conveniencia de un certamen en dos puntos principales:

4 Escrito del director de Administración Civil al gobernador general de Filipinas. Manila 8 de marzo de 1894. El Diario de Manila del 16 de marzo de 1894 copia este documento de la Gaceta de Manila.

5 Esta propuesta se hizo el 2 de septiembre de 1894. Ibídem.

6 La Voz Española de 13 de febrero de 1894. 
1. Si se tenían recursos para ello, debía desde luego organizarse una exposición en la que tomasen parte España, China, Japón, Siam, Anam, posesiones inglesas, francesas, portuguesas, holandesas y danesas, aunque para prepararla debidamente hubiese que retrasar la fecha de celebración.

$2 .^{\circ}$ En caso contrario, el certamen a celebrar serviría como avanzada, para poner de manifiesto los productos naturales e industriales de estas islas y cuantos datos, antecedentes y noticias pudieran servir de base a exposiciones futuras de mayor alcance cuando hubiera dinero. ${ }^{7}$

Terminado el período de información, y como convenía empezar cuanto antes la organización, Avilés propone a Blanco pedir telegráficamente al ministro de Ultramar la autorización del gasto necesario, calculado en 100.000 pesos.

Tras recibir el telegrama por el que el ministro, don Antonio Maura, aprobaba el presupuesto, el gobernador general de Filipinas dispone:

— "El 30 de noviembre de 1894 se inaugurará una Exposición Regional de Filipinas a la que podrán concurrir las empresas, sociedades, propietarios, industriales y artistas, nacionales y extranjeros que deseen. Dicha Exposición tendrá lugar en los terrenos que el Estado posee en el arrabal de la Ermita, donde se halla establecida la Escuela de Agricultura, cuyo edificio convenientemente dispuesto, servirá de Pabellón central.

- Para organizar y dirigir la Exposición, se crea bajo su presidencia, una Junta General, siendo su vicepresidente el director general de Administración Civil y el secretario general, el director de la Escuela de Agricultura de Manila. En ella, tendrán representación las órdenes religiosas, el Ejercito, la Armada, la Administración Pública, los establecimientos de enseñanza, la agricultura, la industria, el comercio y las artes". ${ }^{8}$

Desde que Avilés tuvo la idea de la exposición, en septiembre de 1893, la prensa en general se dedicó a hacer una intensa publicidad sobre la preocupación de España por el desarrollo y prosperidad del país, sobre los beneficios que obtendrían todos los expositores: "para que pueda apreciarse los resultados del ayer con los de hoy", ya que Filipinas estuvo ais-

7 El Comercio de 7 de febrero de 1894.

8 Manila, 9 de marzo 1894. El Diario de Manila del 16 de marzo de 1894 copia este documento de la Gaceta de Manila. 
lada por completo "de la culta Europa". ${ }^{9}$ Se destacaba el gran apoyo del ministro de Ultramar a esta empresa, "que tanto honra la civilizadora misión que España se impuso en Extremo Oriente", preguntándose si el pueblo filipino sabría aprovechar esta ocasión aportando todos los adelantos técnicos, avances industriales y agrícolas y obras de arte y cultura. Para animarlo, la mayoría de los medios de información inician una campaña donde se insiste en que de todo el esfuerzo que hacen las autoridades, tanto españolas como isleñas, los principales beneficiados serán los expositores, pero que de nada serviría si "dejándose llevar por su tradicional apatía y su injustificada desconfianza, no contribuyesen con toda su energía a asegurar el éxito de esta empresa". ${ }^{10}$

Todo estaba preparado. Se confiaba que con la exposición se conocieran los adelantos técnicos extranjeros para mejorar la industria, la agricultura y la ganadería, que según El Diario de Manila se encontraban en un estado muy primitivo: "Nadie desconoce — dice refiriéndose a la agricultura- ... que los naturales usan los mismos medios que usaban los que existían cuando llegó Legazpi". ${ }^{11}$ Con respecto a la crisis pecuaria que atravesaban las Islas, el mismo periódico afirmaba: "Estamos sentenciados a quedarnos sin ganado vacuno, ... que va degenerando de día en día, por multitud de causas ...", por lo que para mejorar esta situación, resultaría imprescindible que se otorgasen premios a los que presentasen el ganado en mejores condiciones y "ofrezcan medios para multiplicar y mejorar las razas". ${ }^{12}$

Cuando se supo que China y Japón no concurrirían, se esperaba que al menos viniesen sus industriales a presenciar el certamen, lo que daría un impulso a la balanza comercial; sin embargo, el tiempo pasaba y muy pocos pedían concursar en el certamen. En los diarios se empieza a censurar la apatía del filipino, y como estímulo a su concurrencia explican una y otra vez las ventajas económicas que pueden obtener, tanto por los premios que consigan como por las ventas que puedan hacer. Esta colabora-

9 El Amigo del Pueblo de 16 de marzo de 1894.

10 La Voz Española de 9 de marzo de 1894.

11 Diario de Manila de 16 de marzo de 1894.

12 Ibídem, 17 de marzo de 1894. Esta opinión sobre el estado de la agricultura y la ganadería no era compartida por todos los medios. El Amigo del Pueblo, de 16 de marzo de 1894, afirma que: "desde la apertura del Canal de Suez, este suelo produce más y mejor, debido en gran parte al conocimiento de los adelantos modernos". Un ejemplo de ello sería la isla de Negros. Si la producción de las islas no aumenta todo lo que debiera — afirma el periódico - es por las trabas que encuentra el agricultor para dar salida a sus productos y, sobre todo, "a esos exorbitantes derechos fiscales que se les exigen a la entrada en España". 
ción de la prensa en los primeros momentos se va transformando en críticas, veladas por la censura, y dentro de un contexto patriótico, pero que revelan las deficiencias de la organización de la exposición, el gasto que supondría, la calidad y cantidad de expositores que participarían, las exclusivas ofrecidas a alguna publicación sobre los acuerdos adoptados por la Junta ${ }^{13} \mathrm{y}$, sobre todo, la mediocridad que resultaría si el certamen se preparaba en tan poco tiempo.

La Semana, de una forma satírica, comienza el bombardeo contra la organización:

"Allá por el mes de octubre de 1893 se dijo poco menos que oficialmente... que en noviembre del 94 se celebraría en Manila una Exposición Regional. Eso se dijo entonces y todos creímos que iba de veras; pero después ha empezado a discutirse en el seno de varias corporaciones, la conveniencia o inconveniencia de que se celebre la anunciada Exposición... y en eso estamos. Lo que yo siento es que a este paso llegará el mes de noviembre y no sabremos si conviene o no conviene". ${ }^{14}$

En el mes de abril aún se estaba pidiendo opiniones sobre la construcción de edificios, concluyéndose que en su mayor parte deberían ser de un solo piso y de entramado de ladrillo.

Esta parsimonia desesperaba a la mayoría de los medios. "Ya va haciendo falta esa urgencia si la Exposición no ha de ser de caña y nipa", ${ }^{15}$ apunta El Comercio. La Semana, con su peculiar estilo, hace una crítica más rotunda:

"Bueno, ya tenemos programa, reglamento, bases, etc., etc.; y una comisión organizadora compuesta de cuarenta o cincuenta vocales, por lo menos.

$$
\begin{aligned}
& \text { Yo pido a Dios que resulte } \\
& \text { La futura exposición } \\
& \text { Tan rica...como de bases } \\
& \text { Y de vocalización". }{ }^{16}
\end{aligned}
$$

Respecto al gasto, El Comercio del 3 de marzo de 1894 habla de la autorización de los cien mil pesos: "Esta suma se aplicará con cargo al sobrante de la Caja Central de Fondos Locales". El periodista estima:

13 Durante casi todo el mes de abril de 1894, El Comercio, Heraldo Militar y La Oceanía Española, entre otros, critican la falta de información proporcionada por las diferentes subcomisiones, la cual sí tenía el Diario de Manila.

14 La Semana de 3 de febrero 1894.

15 El Comercio de 26 de abril 1894.

16 La Semana de 18 de marzo de 1894. 
PRENSA Y CRÍTICA ANTE LA PRIMERA EXPOSICIÓN REGIONAL DE FILIPINAS

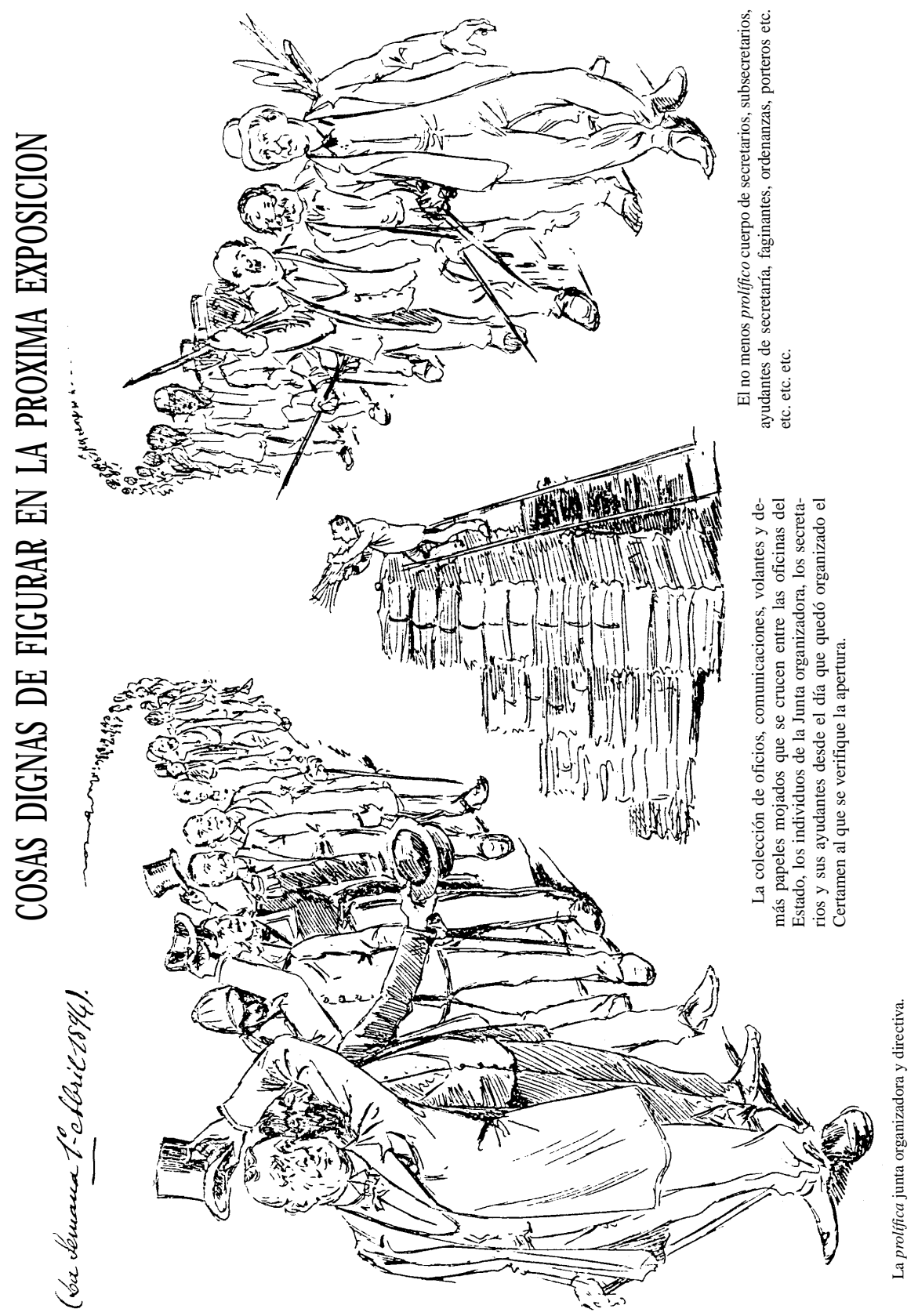


"Vemos que se sigue usando la palabra sobrantes, cuando aquí nada sobra, al contrario, falta mucho...Dígase ...con cargo a las Cajas de Fondos Locales, pero no se haga creer que nos sobran cien mil duros de esa Caja con lo cual quiere decirse que todo está hecho y que no tenemos en qué emplear el dinero".

Empezaron a correr rumores sobre un aplazamiento de la exposición, e incluso que su presupuesto podría destinarse a las necesidades de la campaña de Mindanao. ${ }^{17}$ Rápidamente surgen los desmentidos y la guerra entre periódicos. La Voz Española, El Eco de Filipinas y otros se apresuran a negarlo. "Perfectamente informados, podemos decir....que semejante noticia es completamente inexacta". ${ }^{18}$ Otros llegan más lejos. Si hiciera falta dinero para Mindanao, no sería el de la exposición, "sino que contando con la confianza del Gobierno de S.M. no ha de escatimarle éste ningún recurso". A pesar de ello y mostrando poca confianza en el certamen, aceptan que se retrase, dada la agobiante situación monetaria, la falta de iniciativa y el riesgo de que no estuviese concurrido, "como regularmente sucederá de celebrarse en la época anunciada". Nada tendría de particular entonces —añadían - que los 100.000 pesos tuviesen una aplicación "más útil". ${ }^{19}$

Para terminar con el conflicto sobre las necesidades de Mindanao, $L a$ Voz Española publica el 2 de mayo la noticia de que el ministro de Ultramar ha autorizado telegráficamente al gobernador general para que, con cargo a los sobrantes de la Caja Central de Fondos Locales, pueda invertir 150.000 pesos en las operaciones de Mindanao ${ }^{20} \mathrm{y}$ aunque no desprecia un posible aplazamiento de la exposición por razones de tiempo, "mientras el gobierno no lo anuncie, conviene no propagar esas noticias, para no desanimar a los posibles expositores que pueden creer que se ha desistido de su celebración". ${ }^{21}$

Aprovechando la polémica, El Heraldo Militar da una idea a los "celosos gobernantes": "La Exposición regional primero y después la campaña de Mindanao, nos han dado a conocer un recurso del que se puede fácilmente echar mano, nos referimos a los sobrantes del presupuesto de

17 Diario de Manila de 27 de abril de 1894. Esta noticia la copiaron dos o tres periódicos, entre ellos Manililla.

18 La Voz Española de 28 de abril de 1894. Esta noticia la copió literalmente El Eco de Filipinas del día 29. También la comentaron varios periódicos, como La Oceanía Española de 1 de mayo de 1894.

19 El Heraldo Militar de 1 de mayo de 1894

20 La Voz Española de 2 de mayo de 1894.

21 Ibídem, 5 de mayo 1894. Lo mismo afirma La Oceanía Española de 11 de mayo. 
Fondos Locales". Todo el mundo aplaude que sirvan para sufragar ambos gastos, "pero como ni todos los años ha de haber exposiciones, ni se han de emprender campañas, es indudable que con esos sobrantes pudieran irse acometiendo empresas de verdadera utilidad", por ejemplo, préstamos con interés razonable a los agricultores. ${ }^{22}$

El Diario de Manila se defiende de sus compañeros de prensa que le recriminaron "ir a degüello con la Exposición", por haber dado la primicia del retraso y del posible destino del dinero, diciendo que ellos trasmiten lo que oyen, y que su sección noticiera no podía ser declarada "texto oficial" como la Gaceta. Sobre lo que se haga con el dinero no querían definirse porque, entre otras cosas, "las opiniones de la prensa se estiman en tan poco que, desgraciadamente, hay quien tiene a gala hacer lo contrario de lo que indican los periódicos". Remata su argumento informando que en adelante no emitirían ninguna opinión, porque "sin haber hecho nada se nos señala ya como enemigos declarados, no queremos pensar lo que se nos diría si expusiésemos nuestro franco parecer, en el caso de que éste tuviese la desgracia de no ser el mismo de los que todo lo ven, o lo quieren ver, de color de rosa". ${ }^{23}$

Las críticas a los organismos encargados de la exposición, en comparación a los que hicieron las de París, Barcelona o Chicago, se hacían cada vez más descaradamente. A ellos nos les faltaba tiempo para propagar sus acuerdos, de modo que entusiasmaban al público, mientras que "aquí, han decidido guardar absoluta reserva. ¿Se quiere que una exposición sea muy concurrida?. Pues lo primero que hay que hacer es que no lo sepa nadie". ${ }^{24}$ Esto, unido a la dejadez de los vocales de la subcomisión de propaganda, que en ocasiones no podía reunirse por no haber suficiente número de ellos, era objeto de chanza. "Si tras de que se dispone de poco tiempo, no acuden a las sesiones los señores vocales, es indudable que la propaganda va a ser activísima". ${ }^{25}$

El 11 de mayo se reúne la comisión directiva de la exposición para agilizar los trabajos preparatorios, acordando abrir un concurso y premiar con 1.000 y 500 pesos los dos mejores proyectos que se presenten para los edificios y jardines, ${ }^{26}$ sin tener en cuenta que en el plazo de seis meses los

22 El Heraldo Militar de 8 de mayo de 1894.

23 Diario de Manila de 2 de mayo de 1894.

24 La Oceanía Española de 13 de abril 1894.

25 Heraldo Militar de 30 de mayo de 1894.

26 Heraldo Militar de11 de mayo de 1894. 
autores tendrían que preparar los proyectos y presentarlos a la comisión, y ésta debía exponerlos al público, estudiarlos, juzgarlos y otorgar los premios. Una vez elegido el mejor proyecto, se tendrían que construir los edificios, decorar el interior, arreglar y embellecer los terrenos circundantes, presentar los objetos que habían de exponerse, catalogarlos e instalarlos y todo esto teniendo en cuenta que septiembre y octubre eran meses de lluvias torrenciales y baguios... ${ }^{27}$

Aunque casi toda la prensa está de acuerdo en que el tiempo se echa encima y no hay nada hecho, cada periódico lo achaca a diferentes razones. El Diario de Manila defiende a la organización aludida unos días antes por El Comercio; en efecto, el poco tiempo que queda es el peor por ser el de la temporada de lluvias, pero ni la junta ni la comisión ni el personal son culpables, más bien lo son una serie de circunstancias que han rodeado a los preparativos: lo tarde que se anunció y se constituyeron las juntas, la falta de fondos a tiempo, la ausencia del iniciador del proyecto, señor Avilés (de viaje por China y Japón) y la escasez de medios. Sin embargo, está de acuerdo con los demás periódicos en que en ese período, con la temporada de aguas, las comunicaciones se hacen dificilísimas y la junta ni siquiera podría recibir las contestaciones a su correspondencia, entre otras dificultades, de manera que, antes de que resultase un fracaso, sería mejor retrasarla. ${ }^{28}$

Otro punto de conflicto era la afluencia de expositores, pues - como decía El Comercio - el éxito de este tipo de certámenes depende en gran medida del número de participantes y de visitantes que acuden a ellos; de ahí, la importancia de la propaganda. Pero para que ésta sea efectiva, debe de ser, a su juicio, muy popular y muy "poco centralizada".

"A estas horas, debían de haberse constituido en todas las provincias y pueblos, comités especiales, dirigidos por los alcaldes o capitanes y los párrocos. Así, trabajando todos en común, sin disgregaciones que estorban, sino bajo unificadas instrucciones, que ya debían de estar redactadas, publicadas y profusamente repartidas por la junta central, el éxito en cuanto a la presentación de expositores, no sería dudoso".

27 Heraldo Militar de 11 de mayo y 9 de junio de 1894.

28 Diario de Manila de 26 de mayo. En el mes de marzo varios periódicos dan la noticia de que Ángel Avilés, su hermana y otros iban a Japón y China para estudiar un convenio comercial. Tras un rectificado de esa noticia, se da entre el 14 y 18 de abril la de que al señor Avilés le han concedido licencia de 45 días por enfermo para el viaje a China y Japón. Todos los medios se hacen eco de su partida en el "Hiogo Maru". A finales de mayo pide una prórroga de 22 días, que le es concedida, y cuando volvía tuvo que esperar un tiempo debido a la cuarentena que se había impuesto en Hong-Kong, con lo que no regresa hasta el 13 de julio. En su ausencia se nombró para ocupar la vicepresidencia a don Manuel Asensi. 
Añade que la junta debía hacer conciertos con las empresas de transporte para abaratar los fletes y pasajes, anunciar las tarifas, hacer saber que el Estado corre con los gastos de los envíos de los productos que participen en la exposición y garantiza su devolución, propagar los premios que se pueden obtener y acordar y anunciar el plan de festejos. De lo contrario "no se puede esperar nada de la espontaneidad de los particulares". ${ }^{29}$

El Eco de Filipinas abordó de forma jocosa el problema de la falta de expositores, pero en el artículo, firmado por Manuel Lerinig, se refleja el poco valor que en principio se le otorga al certamen y la denuncia de algunas iniciativas de la administración:

"Líbreme Dios de meterme a discutir si su apertura (de la Exposición) se verificará este año o el que viene, pues para eso, Diario y Comercio tiene Manila ... El objeto de este articulejo, es el de enumerar los que a la Exposición concurrirán; y para eso muchos se me quedarán en el tintero, pues no he tenido tiempo material para ir a preguntar a cada hijo de vecino que chisme o artefacto piensan exponer...

Doña Salomé Carrillos, persona ilustrada con monos en el texto, es decir, con la cara como el empedrado de la calle de Joló, vecina mía y además prima carnal de un carabinero retirado, piensa (cosa que yo juzgaba increíble en ella) mandar a la exhibitión compani, su último vástago, criatura de veinticinco abriles, pero con una nariz como una espuerta... También don Ruperto, persona que vive de lo que come, pero que se ignora cómo se las arregla para hacerlo, está escribiendo a gran velocidad... un estudio sobre la carencia de calderilla en Ilo-Ilo y sus causas. Mucho tiene que devanarse los sesos para saber cuales son éstas; sin embargo, él no para hasta que se dé de bruces en el Hospicio de San José. Don Mariano, punto retirado, no por su voluntad sino por los achaques de la vejez y por un sobrehueso que le ha salido sobre la tibia y el peroné, va a presentar una protesta contra la determinación que han tomado sus acreedores. Y por último, la ciudad de Manila, representada por varias corporaciones, remitirá los objetos que a continuación enumero:

El modelo de monumento que se erigirá a la memoria de los esclarecidos patricios Legazpi y Urdaneta (al pie del modelo estará el retrato del iniciador de tan feliz idea). La primera piedra del teatro Colón, con los periódicos, monedas y actas que con aquélla yacen en profunda sepultura. Tratado sobre construcciones rápidas, redactado por los arquitectos que han construido el edificio Monte de Piedad y Caja de Ahorros de Manila. El presupuesto de las obras del puerto de Manila, documento que podrá servir de estudio a los ministros de Hacienda. Modelo de los puentes en construcción sobre el río Pasing y el estero de Meisíc. (El modelo irá acompañado de un volumen de innumerables páginas, el cual será una Memoria explicativa de las cualidades del cemento Porlan y sus derivaciones). También serán presentados al concurso, los candidatos a la plaza de pintor pensionado por el Ayuntamiento, como personas que simbolizan la paciencia. El Cuerpo de Bomberos en traje de gala. En el acto

29 El Comercio de 22 de mayo de 1894. 
de la apertura de la Exposición, varios individuos del Cuerpo harán diferentes ejercicios con la cuerda.

Y por último, en primoroso estuche, un facsímil de los expedientes en trámite para el tendido del cable a Visayas y para la dotación del personal y material con destino a la Escuela de Artes y Oficios de la Pampanga; cuyo edificio, se está muriendo de risa.

Estos son, que yo sepa hasta ahora, los objetos que serán expuestos en la Exposición Regional..... ${ }^{30}$

A finales de mayo se nombra a don Lorenzo Rocha para que empiece a preparar un concurso sobre el grabado de diplomas y acuñación de medallas para el certamen. Se proyectaban 600 medallas de bronce de seis centímetros de diámetro, llevando en el anverso los bustos de SS.MM. el rey y la reina regente y, en el reverso, una alegoría alusiva al objeto de la exposición. El ganador, obtendría 600 pesos y tendría la obligación de grabar en acero los troqueles y dirigir la acuñación. También se daría un accésit de 100 pesos. Para los diplomas se señalaba un premio de 300 pesos y un accésit de 50; su diseño debía consistir en una composición alegórica a la exposición, de 35 por $55 \mathrm{~cm}$. Hasta el 5 de junio no se publican las bases para el concurso de dos anteproyectos de construcción, uno de edificios y otro de paseos, kioscos, pajareras, etc., y hasta dos meses después no se elige el proyecto del comandante de ingenieros, don Rafael Aguilar, marqués de Villamarín, a quien se encarga la dirección de obras y cuyo lema era "Optium Simplex". ${ }^{31}$ El 14 de junio se abre el concurso para premiar con 250 pesos el mejor anuncio-cartel, a varias tintas, que en su día se imprimiría por el procedimiento cromolitográfico. Los trabajos debían estar entregados el día 25. El ganador de este premio resultó ser el cartel con el lema España conduciendo a Filipinas por el camino de la gloria, de Juan Luna Novicio. ${ }^{32}$ La cuantía del premio también fue objeto de polémicas. Con 100 pesos sería suficiente, "no porque los diseños no merezcan más, sino porque el presupuesto es muy limitado y van corriendo los gastos burocráticos y no estamos todavía más que en periodo de proyectos. Es

30 Eco de Filipinas de 12 de mayo de 1894.

31 Además del premiado, se presentaron los proyectos relativos a edificios: Lara de Levante; Legaspi; Deus, natura et homo facient opus perfecta; Ars longa, vita brevis; Barcelona; A quien Dios se la dé, san Pedro se la bendiga; Path e Inteligencia, actividad, trabajo. La subcomisión propuso declarar desierto el concurso referente a jardines, ya que los anteproyectos presentados no podían llevarse a cabo. La Voz Española de 7 de julio de 1894.

32 Diario de Manila de 25 de mayo, 5, 14, 26 y 27 de junio y 10 de julio de 1894 . Además del cartel ganador se presentaron otros seis con los lemas A Avilés, Las exposiciones son la fuente de la riqueza de los pueblos, España, Ayer, hoy y mañana y No basta que tengas razón, es preciso que te la den. La Oceanía Española de 26 de junio 1894. 
decir: que no se gaste la pólvora en salvas". ${ }^{33}$ El 23 de julio se entregaba al litógrafo sr. Partier el anuncio-cartel para su composición. ${ }^{34}$

Hasta noviembre no se eligen los proyectos ganadores del concurso de diplomas y medallas que resultaron ser para los diplomas el que llevaba por lema Progreso, de Juan Luna Novicio, y para las medallas, Lealtad, de don Melecio Figueroa, profesor de la Academia de Dibujo, Pintura y Grabado. ${ }^{35}$

Esto nos da una idea de cómo estaba la situación en Filipinas; la prensa ya estaba unánimemente de acuerdo en que todo iba tan lento que no daría tiempo de hacer nada en condiciones. El editorial del Eco de Filipinas reflejaba el ambiente que se vivía:

"Discrepamos en la forma y fecha en que se va a celebrar; en la forma, porque nos parece demasiado poco el dinero con que el estado va a contribuir a los gastos y en la fecha, porque dadas las dificultades con las que aquí se tropieza para todo y la fuerza de inercia que hay que vencer en los naturales, nos parece muy escaso el tiempo y prevemos que el certamen va a resultar desairado y no ha de evidenciar entre propios y extraños, que es su principal objeto, el verdadero estado del país en todo aquello que le conviene evidenciar ... Esto no es América sino Filipinas y la febril actividad de los yankees contrasta de manera admirable con la atonía del pueblo filipino, así como contrastan las iniciativas de aquellos con el marasmo de este". ${ }^{36}$

Efectivamente, el presupuesto era escaso. Los 35.000 pesos presupuestados para la construcción de los edificios de la exposición y su cerramiento no tuvieron postor en la subasta que para tal fin se celebró en julio ni en la posterior de septiembre, por lo que las obras se tendrían que ejecutar por el sistema administrativo. ${ }^{37}$

El 13 de julio vuelve Avilés de su viaje a China y Japón y, estudiada la situación a propuesta del secretario de la exposición, se decidió aplazar la inauguración hasta el 23 de enero de 1895, día del santo del rey. ${ }^{38}$

\section{La prensa a favor de la Exposición}

Una de las medidas más acertadas tomadas por la comisión fue la comunicación que don Benito Francia, presidente de la subcomisión de

\footnotetext{
33 El Amigo del Pueblo de 14 de junio de 1894.

34 Ibídem, 23 de julio de 1894.

35 La Voz Española de 18 y 19 de noviembre de 1894.

36 Eco de Filipinas de 17 de mayo de 1894.

37 La Voz Española de 23 de julio y 23 de septiembre de 1894.

38 El Heraldo Militar de 27 de julio de 1894.
} 
propaganda y publicidad, hace a la prensa de que aisladamente o en asociación vayan a la exposición y den a través de sus periódicos la máxima publicidad posible, para que todos se animen a ir. A través de varios medios he tenido conocimiento de reuniones mantenidas con los periodistas; aunque no he podido saber el contenido de éstas, lo cierto es que la actitud de los periódicos cambió radicalmente. De no haber casi noticias se empieza a hablar de la exposición a diario, se notifica cuando algún industrial o empresa piensa concurrir como expositor, cuando se presentan planos de pabellones, los acuerdos con empresas, las peticiones de terreno para hacer instalaciones, etc., pero sobre todo se pasa de pensar que todo iba a ser un fracaso a la esperanza del éxito. Reflejo de este cambio es el editorial de El Comercio:

"La actividad desplegada últimamente es como un desquite a la fría actitud con que comenzó. Los certámenes de esta clase deben tener un mínimo de esplendor, dando vistosidad, porque no sólo se reduce a premiar los mejores productos u objetos de arte de los expositores, sino que en el orden económico son para las ciudades donde se verifican muy provechosos por los ingresos que proporcionan al comercio e industria local la extraordinaria afluencia de viajeros que concurran a la Exposición". ${ }^{39}$

La abundancia de visitantes fue fomentada desde la prensa con todos los recursos propagandísticos a su alcance, desde animar a ir paseando a visitar los trabajos al recinto, dado "el buen estado de la calzada que conduce al campo destinado a la Exposición", ${ }^{40}$ a llamar la atención a los comerciantes e industriales de todo tipo, especialmente a los propietarios de hoteles, fondas y hospederías, a empresas de espectáculos y de alquiler de carruajes, entre otros, para que se preparasen a recibir un gran número de visitantes y no tuviesen pérdidas cuantiosas por su apatía y abandono. ${ }^{41} \mathrm{Se}$ divulga el acuerdo adoptado por las empresas navieras y la del ferrocarril de Manila a Dagupan de rebajar el cincuenta por ciento en los billetes de las personas que con este motivo viajen a Manila, y a la vez que se daba la noticia de que hacendados ricos de la mayor parte de las provincias vendrían a Manila para la inauguración, se publican las normas para su control:

"Es obligación de las fondas y casas de hospedaje dar cuenta a la autoridad competente del número de huéspedes que entran y salen diariamente de sus establecimientos, así como es obligación de cualquier vecino de la ciudad que aloje en su casa a

39 El Comercio de 13 de diciembre de 1894.

40 Diario de Manila de 15 de noviembre de 1894.

41 El Heraldo Militar de 4 de enero de 1895. 
parientes o amigos, dar cuenta de quienes son, sus nombres y demás señas oportunas. Estas son garantías que deben ofrecerse al viajero, que al llegar a Manila tiene la autoridad el deber de saber quien sea aquél, para no escasearle cuantos auxilios deba". ${ }^{2}$

En el afán por dar información sobre cosas relacionadas con el certamen se anunciaban cosas baladíes para los habitantes filipinos, pero que seguramente les resultaban atractivas, como que se había dotado de un uniforme sencillo al personal subalterno de porteros y "faginantes" y que se comisiona al señor Nubla para dirigir la confección de distintivos para los vocales de la comisión directiva, ${ }^{43} \mathrm{o}$ la descripción de los distintivos destinados a los empleados de las diferentes secciones: "Sobre un lazo formado con una cinta de seda y colores nacionales, de dos centímetros de ancho, va colocada una pequeña medalla de plata sobredorada, en la que están grabados los cuarteles centrales de las armas reales. Por la parte opuesta, una pequeña rama de laurel cruza diagonalmente el escudo. Los extremos del lazo van rematados con un fleco de oro. La idea está tomada del distintivo que usan los generales y jefes del Cuarto Militar del rey". ${ }^{44}$

\section{A la búsqueda de expositores}

No obstante el nuevo criterio, a estas alturas (diciembre de 1894-primera quincena de enero de 1895) sólo se tenía noticia de la instalación, como motor de la galería de máquinas de la exposición, de una locomóvil o máquina de vapor y otros aparatos de la extinguida colonia agrícola de Puerto Princesa, cuyo transporte y montaje costaría 800 pesos ${ }^{45}$ de la participación de la Subinspección de Sanidad Militar y de la Inspección de Comunicaciones, ${ }^{46}$ de la Maestranza de Artillería; $;{ }^{47}$ algunos productos de la isla de Paragua, de la que ya se anuncia una participación modesta debido, por una parte, a las dificultades de comunicación entre la cabecera y el interior del territorio, lo que impedía que muchas de las colecciones celosamente preparadas por el gobernador y los misioneros llegasen a tiempo $\mathrm{y}$, por la otra, a haber coincidido la convocatoria del certamen con el rele-

\footnotetext{
42 El Comercio de 13 de diciembre de 1894.

43 Diario de Manila de 3 de enero de 1895.

44 Ibídem, 17 de enero de 1895.

45 Ibídem, 28 de mayo de 1894.

46 Ibídem, 22 de diciembre de 1894.

47 El Español de 17 de enero de 1895.
} 
vo de la mayoría de los padres misioneros, precisamente en el momento que más necesaria era su influencia y sus conocimientos locales, "pues nadie ignora que en poblados de razas selváticas, sin el auxilio del misionero poco o nada se puede hacer". ${ }^{48}$ Los productos, que pudiera enviar Iloilo despertaban gran expectación, aunque tal vez, recordando su participación en la exposición de Madrid de 1887, en algunos medios se dudaba de si allí se había entendido bien el objetivo de la misma.

"Suponemos que habrán evitado el error de creer que los certámenes de esta naturaleza son una exhibición de cosas raras que se hacen como especial capricho, pero que si alguien quiere comprarlas a gran escala no hay forma de conseguirlas". Su industria más apreciada ... "como es la del tejido de sinamay, piña, jusi y seda, necesita presentarse a la Exposición como a un mercado donde se va a ver, a comprar y a estimular el progreso industrial". ${ }^{49}$

La provincia de Cebú estaría representada por unas muestras de carbón de piedra. Esta noticia se aprovecha para criticar la política de explotación minera, que si se hiciera con capital suficiente, liberaría a la industria y navegación insular de los impuestos que tenían que pagar a Australia, Inglaterra y Japón..$^{50}$

La participación de artistas estaba más clara; escultores como Tampico, Arévalo, Gaudinez Vicente Francisco y otros ya habían dado noticias de las obras que pensaban exponer, así como los pintores Luna, Bueso, Martínez, Cascarosa (hijo), Rivera y Mir. ${ }^{51}$ En cuanto a instalaciones particulares, sólo se tenía seguridad de la participación del señor Coso, dueño de la fábrica de ladrillos La Castellana, de la Compañía General de Tabacos, de la destilería La Clementina y alguna más. ${ }^{52}$ La fecha de inauguración se acercaba y todavía no se tenía claro qué se iba a exponer. A mediados de diciembre sólo se tenía seguridad de que concurrirían dos docenas de expositores. ${ }^{53}$ Ante este contratiempo, la comisión se pone manos a la obra. La Dirección General de Administración Civil manda una circular a los jefes de provincias para que, por todos los medios a su alcance, contribuyan a que los diferentes pueblos bajo su mando envíen produc-

48 Diario de Manila de 11 de diciembre de 1894 y 13 de enero de 1895.

49 La Voz Española de 5 de enero de 1895.

50 El Comercio de 15 de enero de 1895. de 1895 .

51 La Voz Española de 3 de diciembre de 1894 y Diario de Manila de 10 y 15 de enero

52 Diario de Manila de 12 y 19 de diciembre de 1894.

53 La Voz Española de 23 de enero de 1895. 
tos a la exposición. Para facilitarles la labor, se les proporciona un catálogo de las personas que presentaron "objetos y frutos" en la exposición general de Filipinas (Madrid, 1887), para que pudieran dirigirse a todos aquellos que, habiendo figurado en aquel certamen, hasta ahora no habían hecho ninguna gestión para presentarse en la regional. ${ }^{54}$

Don Benito Francia, presidente de la subcomisión de propaganda, invitó a concurrir a los centros más prestigiosos como la Universidad de Santo Tomás o el Colegio de Farmacéuticos, así como a algunas personalidades en las Islas como don Anacleto del Rosario, reputado químico y micrógrafo. En principio todos aceptaron llevar trabajos científicos que diesen una idea clara del nivel intelectual alcanzado por Filipinas, aunque pocos días después, el Colegio de Farmacéuticos, en vista del poco tiempo que les quedaba para ofrecer algo digno, declinó la invitación a nivel colegial, aunque participó que sus socios podrían presentar estudios a título personal. ${ }^{55}$

La Academia Pedagógica también envió una circular a todos los maestros del archipiélago para que exhibieran objetos y trabajos propios del magisterio. Se pide auxilio a la prensa para que publique todos los avisos, ya que, dadas las deficiencias del correo, es posible que todos no hubiesen recibido la notificación; aún así, por los periódicos debían darse por enterados. ${ }^{56}$

El director de la Escuela de Agricultura, don Manuel del Busto, comisiona a un empleado de la misma para ir a las provincias cercanas a la capital, para recoger y coleccionar útiles y aperos de labranza, desde los más primitivos a los más modernos, y máquinas y artefactos para la molienda de la caña, descascarillado del palay, desfloramiento del abacá y otros, con el fin de presentarlos debidamente catalogados y clasificados. La primera visita sería a la provincia de Bataan, en cuyo pueblo Samal se esperaba encontrar curiosos útiles de agricultura. ${ }^{57}$ Por otra parte, la prensa publica que las empresas navieras y la del ferrocarril de Manila a Dagupan han determinado transportar gratis los objetos que se presenten a la exposición. ${ }^{58}$

54 Diario de Manila de 17 de noviembre y La Oceanía Española de 18 de noviembre de 1894. La misma noticia, pero referida sólo a Iloilo, la refleja El Porvenir de Bisayas de 23 de noviembre de 1894

55 Ibídem, 6 y 12 de diciembre de 1894.

56 El Comercio de 13 de diciembre de 1894.

57 Ibídem, 17 de diciembre de 1894.

58 La Voz Española de 19 de diciembre de 1894. 


\section{Los obreros y la construcción}

Debido a la publicidad, parece que todo se iba animando. El 15 de octubre empezaron las construcciones y con gran pompa se informaba en el mes de noviembre que las obras de la exposición estaban muy avanzadas: "ya están colocados todos los pies derechos de las edificaciones que se preparan"; ${ }^{59}$ sin embargo se cometen errores, quizá porque con las prisas no se piensa en las consecuencias, como el de tener que desmontar todas las cubiertas de hierro galvanizado de las cuadras y establos y reemplazarlas por unas de madera para evitar las repercusiones que las metálicas, "podrían causar en las observaciones magnéticas por la proximidad al Observatorio de los Jesuitas". ${ }^{60}$ Se tiene que ampliar al 16 de enero el plazo para obtener las primas prometidas si las construcciones se terminaban el día $6 .{ }^{61}$

Pero estos fallos no achicaban el ánimo de la prensa, que insistía en que los trabajos se estaban llevando a cabo "con una rapidez pasmosa y digna de los Estados Unidos". "Somos de la opinión, dice El Eco de Filipinas, que tan activos obreros figuren en la Exposición como ejemplares nunca vistos en el Archipiélago". ${ }^{62}$ Además de trabajar bien, debían trabajar bien protegidos, porque en toda la obra, solo hubo un "lisiado", al que el señor Avilés dio 10 pesos como donativo. ${ }^{63}$

Todas estas alabanzas a los obreros de la exposición podían hacernos pensar que los indígenas habían cambiado de actitud y se habían implicado definitivamente en el proyecto; sin embargo, la crítica que sobre ellos hace El Español nos indica que, como siempre, el trabajo cotidiano en Filipinas era casi exclusivamente de los chinos, "que sumisos a su cabecilla, sin escuchar más que su voz, trabajan horas y horas y por fin entregan las obras recibiendo por ellas el salario estipulado. Su único interés es la retribución y no el cariño a un trabajo noble y honrado". Un periodista llegó a escribir:

"Sentimos pena e indignación ante la idea de que por su modo de ser especial, por su tibieza de carácter y por la ausencia de grandes necesidades, el indio nacido en este fértil suelo y al amparo de la noble España, se deje despojar impunemente por abandono e indiferencia de uno de los veneros de riqueza, el trabajo." ${ }^{4}$

59 El Comercio de 20 de octubre y Diario de Manila de 15 de noviembre de 1894 y 18 de enero de 1895 .

60 Ibídem, 7 de diciembre de 1894.

61 Diario de Manila de 3 de enero de 1895.

62 El Eco de Filipinas de 13 de enero de 1895.

63 La Voz Española de 23 de enero de 1895.

64 El Español de 12 de enero de 1895. 
A pesar del impulso, muchas instalaciones no estaban terminadas para la inauguración, entre otras las de La Insular, Compañia General de Tabacos, Ayuntamiento de Manila, varias casetas de materiales ligeros para restaurantes y refrescos y la del Arsenal Civil de Barcelona, por no haber llegado los materiales para su construcción.

\section{Las fiestas proyectadas}

La afluencia de público a la exposición era un tema que tenía preocupada a la organización de la misma; por un lado, porque sería el termómetro que indicara su éxito y, por otro, porque ya que el certamen se entendía no sólo como un alarde de su industria, agricultura, comercio, etc., sino también como una manera de que todos aprendieran de lo expuesto. Para que esto sucediera había que despertar, con el reclamo de los festejos, el interés por acudir al recinto, porque — como indica El Comercio- "por desgracia, la sociedad actual es frívola, por lo que, junto a los alardes de la industria y los avances en el comercio y la agricultura, se debe poner lo sublime de la poesía; ante la máquina de vapor, la música; frente a un invento mecánico, una joya artística de mérito. Así, la multitud, en busca del pasatiempo, se pone sin apenas notarlo, frente a lo práctico y útil, y con ello, aprende". ${ }^{65}$

La prensa empieza a dar ideas sobre los festejos que deberían prepararse y, a la vez, anunciaban los proyectos ya elaborados para animar al público. Ignoro si todos se llevarían a cabo; sin embargo, creo que las disposiciones en este tema nos pueden dar una idea de cómo se planteaba la sociedad filipina de la época un certamen de estas características.

En lo primero que se piensa es en arreglar la ciudad, por lo que se encarga a los gobernadorcillos de los arrabales levantar arcos triunfales en las calles principales de sus jurisdicciones como en el de Tondo, desde la iglesia hasta el puente de Joló, plaza de Calderón de la Barca, Rosario, San Fernando, Escolta, plaza de Goiti, Carriedo, calzada de San Sebastián, Alix, hasta la rotonda de Sampaloc, la de Malacañang, General Solano, San Miguel, Echagüe; desde el puente de España hasta la puerta de Parián, calle Real de Manila, hasta la puerta de Santa Lucía, calzada de las Aguadas, calle Real de la Ermita y Malate, Paco, San Marcelino y toda la extensa cal-

65 El Comercio de 11 de enero de 1895. 
zada de Iris, desde la orilla del mar hasta la plaza de Santa Ana. Los arcos debían distanciarse 100 metros y estar bien adornados, con faroles para su iluminación; también debían decorarse con gallardetes y abullonados los puentes de España, General Blanco, Ayala y Colgante.

Como se esperaba a un gran número de forasteros, con lo que podría colapsarse el tráfico por el puente de España, se acordó subvencionar a los propietarios del puente colgante para que dejasen libre el paso por éste. ${ }^{66}$

Para el día de la inauguración se proyectó una procesión cívica que, partiendo a las tres en punto de la tarde del palacio de Malacañang, recorrería las calzadas de San Rafael, San Sebastián, Carriedo, Escolta, puente de España, puerta de Parián, calle Real, puerta de Santa Lucía, paseo de María Cristina, calle Real de la Ermita y calle del Observatorio, hasta entrar en la exposición.

La procesión se organizaría de la siguiente manera:

1. ${ }^{\circ}$ Un escuadrón de lanceros compuesto por veinte jinetes vestidos a la federica, precedidos de timbales y cornetas, con caballos bien enjaezados.

2. ${ }^{\circ}$ Carros alegóricos de cada una de las provincias del archipiélago presentando sus industrias, tirados o por dos parejas de caballos empenachados y ricamente vestidos o por animales propios del país, como toros, carabaos o aves grandes de papel, empujadas por hombres en el interior. El último carro debía ser el de la provincia de Manila, representando a España y Filipinas con un gran león sobre el mundo. Cada carro iría acompañado por una banda de música.

3. ${ }^{\circ}$ Comisiones de las corporaciones eclesiásticas, civiles y militares, en coches descubiertos, tirados por una pareja de caballos empenachados.

4. ${ }^{\circ}$ Coches descubiertos conduciendo a las autoridades, tirados por dos parejas de caballos empenachados.

5. ${ }^{\circ}$ El Cuerpo de Estado Mayor a caballo.

6. ${ }^{\circ}$ Un gran coche triunfal descubierto, tirado por cuatro parejas de caballos, conduciendo al gobernador general y sus ayudantes.

7. ${ }^{\circ}$ Todos los generales francos de servicio a caballo.

8. ${ }^{\circ}$ El escuadrón de caballería.

9. Un piquete de artillería con banda de música y gastadores.

66 Ibídem, 11 de enero de 1895. 
10. ${ }^{\circ}$ La procesión debía ir escoltada, a ambos lados, por dos filas de soldados del ejército, vestidos de gala, con el arma terciada, con el fin de abrir paso e impedir a la gente que se echase encima de la procesión.

11. Llegada ésta al recinto de la exposición, se disolvería, procediéndose a su apertura e inauguración.

Para el segundo día se proyectó una gran batalla naval en la bahía, con fuegos artificiales, frente al paseo de la Luneta. Esta batalla estaría protagonizada por 30 pagodas.

El tercer día, a las cuatro de la tarde y por las calles señaladas con arcos, se daría un gran paseo de gigantes, enanos, mujeres y hombres representando las diferentes razas del mundo y del país, con sus trajes peculiares, acompañados de una orquesta de 50 individuos, compuesta solamente por guitarras y bandurrias con bajos de cuerda. El paseo partiría del Ayuntamiento y se disolvería en la exposición. ${ }^{67}$

Otros festejos preparados eran un baile de gala en el palacio de Malacañang, otro baile de niños en el salón del Ayuntamiento, conciertos musicales, regatas en el Pasing, concursos de "belleza y virtud", batalla de flores en La Luneta, con premio al carruaje más elegante, funciones en el teatro Zorrilla, ${ }^{68}$ fuegos artificiales especiales, contratados por el Ayuntamiento, para el domingo siguiente a la inauguración. El pirotécnico se comprometía a cumplir con un grandioso programa, que si gustaba al público sería recompensado con una gratificación de 50 pesos sobre el precio estipulado. En caso contrario, se rebajaría del precio convenido una cantidad alzada, que se destinaría a establecimientos benéficos. ${ }^{69}$

La comisión directiva empieza a hacer gestiones para que las bandas militares toquen todas las tardes en el recinto de la exposición, en lugar de hacerlo en la Luneta. Al Diario de Manila le pareció muy acertada esta medida, pero para que la gente prefiriera ir al recinto, en lugar de a los paseos, propone arreglar el piso para poder andar sin molestias y colocar bancos o sillas. Si la comisión no pudiera permitirse este gasto, debía autorizar a

67 Ibídem.

68 La Oceanía Española de 13 de enero de 1895.

69 Diario de Manila de 16 de enero de 1895. Los fuegos artificiales se harían en la bahía de Manila de acuerdo al siguiente programa: 2.000 cohetes de bomba de los llamados desaparecidos, 1.500 bombas pequeñas, 1.500 bombas reales, 50 morteros, 50 bombas con flores, 50 meteoros de Arstrom, 100 bombas meteoras de bomba, 100 de paracaídas y 100 de luces, 5 grandes piezas de 10 varas por 5 varas y 6 piezas de mosaicos de varios modelos. 
algún industrial para llevar sillas de alquiler por un precio módico, como en la Luneta. ${ }^{70}$

El municipio, como parte de los festejos, se proponía contratar para varias funciones en el recinto de la exposición a la compañía de Carvajal. A la prensa en general le pareció bien la actuación de un circo, aunque veía mejor que se representasen piezas lírico-cómicas en español. ${ }^{71}$ También La Voz Española propone al Manila Jockey Club celebrar carreras extraordinarias de caballos en enero y así aumentar con un número más el programa de festejos preparados..$^{72}$ Además, como no todas las instalaciones estaban terminadas el día de la inauguración, para animar a su visita cuando lo estuviesen, sus propietarios preparaban distracciones varias, entre ellas, "una fiesta andaluza que promete ser de mucho efecto"..$^{73}$

La entrada al recinto sería gratis excepto los jueves por la tarde, que se pagará a razón de media peseta, una peseta, medio peso y un peso, según se tratara de peatones, jinetes y vehículos de dos o cuatro ruedas. ${ }^{74}$

\section{El día de la inauguración}

Por fin llegó el 23 de enero. Al apuntar el sol, una salva de 21 cañonazos anunció a la ciudad la onomástica de Alfonso XII y pocas horas después se celebraba en la catedral un grandioso Te-Deum. Terminado éste, se dio una recepción en Malacañang. Pero la verdadera fiesta fue por la tarde ${ }^{75}$ cuando a las cinco y media la fila de carruajes llegaba hasta la antigua plaza de toros, ya que, a pesar de las medidas adoptadas, los coches tardaban cerca de una hora en llegar a la exposición, pues como se había corrido la voz de que no se pedían las invitaciones en la entrada para la ceremonia de inauguración, el gentío era inmenso. ${ }^{76}$

En el patio formado por los cuatro edificios principales de la exposición, adosado al de la Escuela de Agricultura y dando frente al pabellón central, se dispuso una tribuna rodeada de gallardetes que ostentaban el

70 Diario de Manila de 26 de enero de 1895.

71 La Voz Española de 29 de enero de 1895.

72 Ibídem, 23 de noviembre de 1894.

73 Diario de Manila de 20 de febrero de 1895.

74 El Comercio de 21 de enero de 1895.

75 Ibídem, 27 de enero de 1895.

76 La crónica de la fiesta de inauguración la hacen desde distintos puntos de vista los periódicos: El Español, El Comercio, La Voz Española y el Diario de Manila. 
escudo de España, bajo un artístico dosel, al lado del cual se veía el retrato al óleo de la reina regente y el rey, cedido para el acto por don Ildefonso Tambunting, y un busto del rey, obra del señor Arévalo. El gobernador general ocupó la presidencia en el estrado junto a otras personalidades, y desde un pequeño altar don Silvino P. Tuñón, gobernador eclesiástico de la archidiócesis, bendijo el certamen. Terminada la bendición, don Manuel del Busto, secretario general de la exposición, leyó la real orden de convocatoria y prórroga de apertura de 9 de marzo y 27 de julio de 1894, e inmediatamente después el director de Administración Civil, señor Avilés, pronunció el discurso inaugural, el cual concluyó con elogios patrióticos a don Antonio Maura, al rey, a don Ramón Blanco y al pueblo filipino. ${ }^{77}$

Después, el gobernador general visitó, uno por uno, los pabellones y cuando se marchó, la concurrencia de público fue tan numerosa que por algunos sitios apenas se podía transitar. Se calculó que fueron "más de 20.000 las personas que visitaron el recinto, desde el anochecer a las $10 \mathrm{del}$ la noche y no bajaron de 1.000 los vehículos de todas clases que llenaban las calles adyacentes al lugar del certamen". Este llamativo número de visitantes no se mantuvo durante muchos días, por lo que la organización, en vista de las pocas personas que visitaban la exposición por la mañana, decidió abrir sólo desde las 4 de la tarde a las 11 de la noche y cerrar los días siguientes a los festivos, para limpiar el local. Estas medidas suscitaron algunas críticas porque, aunque se habían publicado en los periódicos, "como por desgracia eran muchos los que no leían la prensa", por ignorancia acudieron al recinto, por lo que se recomienda poner carteles en las inmediaciones con gruesos caracteres y en varios idiomas, incluso en chino. Además, la restricción en el horario de visita perjudicaba a los que "iban a aprender" a la exposición, ya que a partir de las cinco oscurecía y casi ninguna sección estaba suficientemente alumbrada. Al margen de estas discrepancias, hay que destacar la afluencia de los indígenas de ambos sexos, que con avidez procuraban enterarse de todo y de personas venidas de provincias. $^{78}$

77 Avilés, Ángel: Discurso del Excmo e Ilmo. Sr. D. Ángel Avilés. Director General de Administración Civil, en el solemne acto de inauguración de la primera Exposición Regional de Filipinas. Manila, 1895. Esta edición fue costeada por el personal de la Dirección General de Administración Civil. En Biblioteca Municipal de Córdoba. Sobre la Exposición Regional en sí, la fiesta de inauguración con el discurso inaugural, la descripción del recinto y la relación de productos expuestos, véase mi trabajo "La primera exposición regional de Filipinas a través de la prensa local del momento", Revista Española de Estudios del Pacífico, en prensa.

78 El Comercio de 20 de octubre de 1894, Diario de Manila de 25 y 27 de enero de 1895 y La Voz Española de 29 y 31 de enero de 1895. 


\section{Resultado de la Exposición}

Los objetivos principales de la exposición eran poner de manifiesto la riqueza potencial de Filipinas, hacer un alarde de los progresos técnicos y estrechar lazos con España y las otras naciones.

Ya hemos visto cómo, por distintas circunstancias, no hubo una participación internacional y pienso que tampoco fueron a visitarla sus industriales, porque la prensa, que publica una y otra vez la cantidad de visitantes que llegan de provincias, no hace mención de la presencia de extranjeros o peninsulares en el certamen. Tampoco, a la vista de los objetos expuestos, se dieron a conocer demasiadas novedades técnicas. El único producto que se anunciaba como novedoso, la xilolita, ${ }^{79}$ no se encuentra en ninguna de las relaciones de productos exhibidos que hacen los periódicos. Lo que sí sirvió fue para que los habitantes de Filipinas, a través de su prensa, se sintieran orgullosos de su tradición y de su cultura y tomara conciencia de su riqueza potencial.

Además de criticar fallos de la propia exposición, como que no hubiese una sección exclusivamente marítima, siendo el mar su principal fuente de ingresos, o no saber si los edificios construidos se derribarían una vez terminada ésta, lo que se consideraba un despilfarro, ${ }^{80}$ los medios aprovecharon sus crónicas para sacar a la palestra todas sus carencias. En efecto, con la excusa de hacer propaganda para que la exposición estuviese concurrida, El Porvenir de Bisayas publica, entre alabanzas al gobierno:

"Quizás sean estas Exposiciones la muestra mejor del interés con que miran los gobernantes a los gobernados... El pueblo filipino está interesado en demostrar con esta ocasión que no es un pueblo inculto, atrasado, rudimentario, y todo su afán debe encaminarse a poner de manifiesto que tiene disposición ingénita para el progreso, el vehemente deseo de adquirirlo y la carencia de medios para lograrlo: su misión consiste en presentar cuanto es, significar cuanto desea y demandar lo que necesita". ${ }^{.1}$

79 El Español de 9 de enero de 1895 hace publicidad de un producto novedoso que pensaba presentarse en la Exposición. Se llamaba xilolita y la describe como semejante a la madera, es susceptible de labrarla, cepillarla y tallarla, puede aceptar el tornillo, clavo y cola para unir las diferentes piezas, acepta toda clase de pinturas y barniz y se puede utilizar en todos los trabajos que se necesite madera, desde la escultura a la construcción. Tiene las ventajas de ser más barata y más fácil de labrar y trasportar, pero sobre todo era incombustible y refractaria a la humedad.

80 Diario de Manila de 6 de febrero de 1895.

81 El Porvenir de Bisayas de 28 de noviembre de 1894. 
En el mismo contexto y refiriéndose a lo que se debe de exponer, el mismo periódico explica:

"Lo que debe procurarse es retratar al país con fidelidad extrema y exactitud matemática, a ver si, ante los defectos de la copia, aprendemos a corregir los del original. Esta es la ventaja indiscutible de la Exposición... Como alarde de exhibición y muestra de perfecciones, sería ridículo: Como juiciosa revelación de lo que somos y podríamos ser, el concurso del 23 de enero resultará un acertado y oportuno procedimiento de gobierno". 82

De esta manera se expresa la prensa en general, aunque algunos medios aprovechan las descripciones de las diferentes secciones para ahondar en distintas reivindicaciones. Como muestra, destacaré algunas de las más exigidas.

La minería: "al visitar la sala destinada a la misma... hemos comprendido que, si Dios no lo remedia, la minería y metalurgia son, por ahora, cosa perdida en Filipinas. En este año de 1895, no contamos con una sola mina de carbón en explotación formal. Si se obtuviera, Filipinas podría contar con una flota de cabotaje que cobrara los fletes baratos, con lo que se multiplicaría las explotaciones agrícolas y comenzaría a renacer la vida industrial". ${ }^{83}$

Otra queja se refería a la política forestal, relacionándola con la copra o carne de coco seca, que a pesar de no haber estado representada en la exposición, es un nuevo y rico ramo de la exportación. "El día que el ministro de Ultramar, previamente asesorado de esta Inspección de Montes, se decida a dotarnos de un liberal Reglamento para explotaciones forestales en Filipinas, en que desaparezcan las enojosas trabas y se rebajen considerablemente las cuotas altísimas que se pagan al Estado por pie cúbico, se habrá iniciado para este país una nueva era de magníficos y florecientes negocios madereros y forestales, con mayores rendimientos para la real hacienda... en vez de los mezquinos y poco productivos por el efecto de las susodichas trabas". ${ }^{84}$

La sección de industria demostró el estado primitivo en el que se hallaba. “Dónde están las fábricas de artículos de primera necesidad como papel, bujías, fosforo, hilado, etc.?, —se pregunta El Comercio_. Ojalá que esta desilusión sirva para implantar alguna de las más necesarias". ${ }^{85}$

82 Ibídem, 13 de enero de 1895.

83 El Comercio de 8 de febrero de 1895.

84 Diario de Manila de 24 de febrero de 1895.

85 El Comercio de 24 de enero de 1895. 
En definitiva, vemos cómo a pesar de todos los esfuerzos de la Administración por estrechar las relaciones con la metrópoli, la mayoría de la prensa, que insiste en la fortuna de pertenecer a España, que dio a las Islas cultura, paz y religión, utilizan la palabra país para referirse a Filipinas y demandan reformas socioeconómicas e inversiones fuertes de capital como única alternativa para que el progreso del archipiélago caminase unido al de la península. 